\title{
The relation between preschool children's language development and their mothers' depression and anxiety symptoms: a cross-sectional study
}

\author{
Zeynep Göker, Havva $\operatorname{Eser}^{2} \odot$, Arzu $^{1}$ Yılmaz $^{3} \odot$ \\ ${ }^{1}$ Department of Child Psychiatry, University of Health Sciences, Ankara Child Health and Diseases Hematology and Oncology Training \\ and Research Hospital, Ankara, Turkey \\ ${ }^{2}$ Department of Child Development and Education, Ankara Training and Research Hospital, Ankara, Turkey \\ ${ }^{3}$ Department of Child Neurology, Ankara Training and Research Hospital, Ankara, Turkey
}

\section{ABSTRACT}

Objectives: In this study, the relationship between preschool age group children's language development and depression/anxiety symptoms of their mothers was investigated.

Methods: Children aged 13-75 months and their mothers were included. Denver-II test and Beck Depression and anxiety scales were utilized. SPSS 17.0 program was used and $p<0.05$ was considered as significant.

Results: Of the 58 patients, $74.1 \%$ were male, with the mean age of 53.3 months. The mean maternal age was 31.5 years. The mean education level was 8.3 years for mothers. According to the Denver-II of language development, $53.4 \%$ of the cases were found to be "delayed" whereas $46.6 \%$ of all were "normal", with significantly lower in "delayed" children (47.4 vs. 60 months; $\mathrm{t}(56)=-3.431, p=0.001)$. Delayed language was significantly associated with lower mothers' education level ( 7.4 vs. 9.3 years; $\mathrm{t}(56)=-2.466, p=0.017)$. The median score of depression scale was significantly higher in the delayed language (18 vs. $13 ; \mathrm{z}=-2.218$, $p=0.027)$. Positive correlation was found between the mothers' education and the language development $(\mathrm{r}=$ $.324, p=0.013)$. The anxiety symptom levels of the mothers were not associated with language development $(p>0.05)$.

Conclusions: The level of education of mother seems to affect language development. There is a relationship between the depressive symptoms of the mother and the delay in language development. It seems important that the mothers of the cases whose children had language development to be directed to psychiatric evaluation. Keywords: language development, child, mother's depression, mother's anxiety

L anguage is one of the important parameters of early childhood development [1]. It is thought that both the receptive language and the expressive language development through social communication skills in the first and second years of life, and then the progressive games, sharing common interests with others, and using gestures and gestures to indicate their needs and desires [2]. Therefore, being aware of the factors affecting language development in early childhood is very important for the healthy development of the child.

The attitude and behavior of the caregiver is the

How to cite this article: Göker Z, Eser H, Yllmaz A. The relation between preschool children 's language development and their mothers'depression and anxiety symptoms: a cross-sectional study. Eur Res J 2020;6(3):193-199. DOI: 10.18621/eurj.475930

Address for correspondence: Zeynep Göker, MD., University of Health Sciences, Ankara Child Health and Diseases Hematology and Oncology Training and Research Hospital, Department of Child Psychiatry, Ankara, Turkey.E-mail: zeynepgoker@hotmail.com, Fax:+90 3123472330 
leading one. Ekerim and Selcuk [3] showed in a study that the warm and supportive attitude of the mother towards her child influenced the effective use of the child's language. The factors that negatively affect the mother's outward behaviors such as depression or anxiety in the mother may negatively affect the child's developmental stages. Depression in mothers leads to both internal and external-problems [4], has a negative impact on children's language development [5], these children were shown to be less than their peers at the age of 1 to 3 years, with less vocabularies compared to children without depression in their mothers [6]. In a cohort study, Koutra et al. [7] showed that neuro-developmental steps including language development of 18 months-old children were adversely affected by depression in the mother. In another prospective study, it was reported that anxiety, perceived stress and depression in the mother had a slight negative effect on the cognitive development of the child [8].

The hypothesis of this study is that "mothers of children aged 12-75 months who have delayed language development have more depression and anxiety symptoms than children with normal language development.

\section{METHODS}

The sample of the study was conducted between May 2018 and June 2018 in Ankara Training and Research Hospital, Hüseyingazi District Polyclinic. Fifty-eight children and their mothers who did not use any language other than Turkish and accepted to participate in this study were formed. Patients with organic (eye, ear pathologies), neurological and syndromic reasons were excluded from the study.

Sociodemographic data were collected by a form prepared by the researchers. The monthly income level variable was reported in three categories as low income (1-1999 Turkish Liras [TL]), middle income (2000-4999 TL) and high income (5000- and above TL) level. Denver II-developmental screening test were applied to the children's mother by child development specialist and Beck depression and Beck anxiety scales were fullfilled by their mothers.

Children who were compatible with their peersas a result of Denver test were taken as control group. Mothers' depression and anxiety symptom levels were expressed in terms of total score of the scale.

The approval of the ethics committee of the study was obtained by the decision of the Ministry of Health, Ankara Health Research and Application Center Medical Research Institute 2018-45-462. Verbal and written informed consent of the mothers were included in the study.

\section{Tools Used}

\section{Sociodemographic Data Form}

It was created by the authors to gather information about the sociodemographic characteristics of children and their parents and siblings. The age of the child, gender, demographic variablesofparents (age, educational status and occupation), monthly income levels, number of children at home, and the presence of a medical or psychiatric disease history in the family and themselves were questioned.

\section{Denver-II Development Screening Test (DDST)}

Prepared in 1967 by Frankenburg et al. [9] is a standardized practice that is adapted to many countries' own communities. The validity and reliability study of the test was conducted by Anlar et al. [10]. It is a test which can be applied easily for children between 0-6 years of age and it has an important role in early development of child development and developmental deviations. Four areas are evaluated in the test:

1. Personal-social: Agreement with people, the ability to meet individual needs,

2. Fine motor: Hand-eye coordination, use of small objects, problem-solving ability,

3. Language: Hearing, comprehension and use of language, receptive and expressive language skills,

4. Rough motor: Movement of large muscles such as sitting, walking, jumping.

The results of the test are grouped in three classes as "normal", "suspicious" and "abnormal". Normal means no delay and no more than one warning, suspicious stands for that there is a delay and /or two or more warnings, Abnormal means there are two or more delays [11]. The cases with normal results are evaluated 3 months later and the suspected cases are evaluated with a test repetition after 1 month. Patients who are considered suspicious or abnormal results are referred to an advanced center for diagnostic evaluation. Since our study was based only on 
language development, the results were reported as in delay and included in a 1-month cross-section.

\section{Beck Depression Inventory (BDI)}

This is a 21-item self-report scale developed by Beck et al. [12] in 1961, presenting the most common emotional, somatic, cognitive, and motivational symptoms in depression. It focuses more on the cognitive and emotional symptoms of depression, with less emphasis on somatic symptoms (including loss of appetite, weight loss, and libido). The items of the scale are rated between 0 and 3 and the lowest total score is 0 and the highest total score is 63 . Increased score means that the level of depression symptoms increases. The Turkish validity of the scale was conducted by Hisli [13] in 1988.

\section{Beck Anxiety Inventory (BAI)}

It isa self-assessment scale used to determine the frequency of anxiety symptoms experienced by individuals developed by Beck et al. [14]. It is a Likert type scale which is composed of 21 items and scored from 0-3. The Turkish reliability and validity was conducted by Ulusoy et al. [15] in 1998.

\section{Statistical Analysis}

Statistical analysis of the data was performed using the SPSS 17.0 program (Chicago Inc., 2008). The conformity of continuous variables to normal distribution was tested with Kolmogorov-Smirnov. Categorical variables were given in terms of number and percentage, and continuous variables were given as arithmetic mean and standard deviation. Student-t test was used for paired group comparison because the data were normal distribution. In the correlation analysis of continuous variables, Pearson, categorical etc. Spearman correlation coefficients were used for correlation analysis of continuous variables. A $p<0.05$ was considered significant.

\section{RESULTS}

Of 58 patients, $73.6(n=43)$ were male and $25.9 \%$ $(\mathrm{n}=15)$ were female. The mean age was $53.3 \pm 15.1$ months (range: 13-75 months). The mean age of the mothers was 31.5 years (mean age: 36 years). The mean education level of the mothers was $8.3 \pm 3.1$ years and the mean education level of fathers was 8.6 \pm 3.2 years.

According to the Denver-II developmental screening test, $34.5 \%(\mathrm{n}=20)$ of the cases were "normal", 36.2\% $(\mathrm{n}=21)$ were "suspicious" and $29.3 \%(n=17)$ were "abnormal". When the results of the language-development subscale were evaluated, it was found that while $46.6 \%(n=27)$ of the cases had normal language development, whereas 53.4\% ( $\mathrm{n}=$ 31) had delayed language development.

The mean age of the patients with delayed language development was significantly smaller than the normal ones (47.4 vs. 60 months; $\mathrm{t}(56)=-3,431$, $p=0.001)$. It was determined that maternal education duration ( 7.4 vs. 9.3 years; $t(56)=-2.466, p=0.017$ ) was significantly lower in patients with delayed language development.

Maternal age variables were found to be similar to those in normal or delayed language development according to Denver-II test $(p>0.05$ for both, see Table 1).

Table 1. Demographics and their relation with language development

\begin{tabular}{lcccccc}
\hline & \multicolumn{2}{c}{ Denver-II language outcome } & & \\
\hline & Total & Normal & Delayed & & \multicolumn{2}{c}{ Statistics } \\
\cline { 5 - 7 }$(\mathbf{n}=\mathbf{5 8})$ & $(\mathbf{n = 2 7 )}$ & & $(\mathbf{n = 3 1 )}$ & $\mathbf{t}$ & $\mathbf{p}$ \\
\hline Age (months) & $53.3 \pm 15.1$ & $60.0 \pm 13.4$ & $47.4 \pm 14.2$ & -3.431 & $\mathbf{0 . 0 0 1}$ \\
\hline Mothers' age (years) & $31.5 \pm 5.4$ & $30.5 \pm 4.9$ & $32.4 \pm 5.8$ & 1.369 & 0.176 \\
\hline Fathers' age (years) & $36.4 \pm 6.6$ & $35.3 \pm 5.4$ & $37.3 \pm 7.4$ & 1.143 & 0.258 \\
\hline Mother education (years) & $8.3 \pm 3.1$ & $9.3 \pm 2.9$ & $7.4 \pm 3.0$ & -2.466 & $\mathbf{0 . 0 1 7}$ \\
\hline Father education (years) & $8.6 \pm 3.2$ & $9.4 \pm 3.1$ & $7.9 \pm 3.1$ & -1.822 & 0.074 \\
\hline
\end{tabular}

Data are shown as mean \pm standard deviation 
Analysis of categorical variables

It was determined that $6.4 \%(n=3)$ of the cases were parents / divorced. $91.5 \%(n=43)$ of the patients were with their parents. $2,1 \%(\mathrm{n}=1)$ of the patients died. $85.1 \%(n=40)$ of the mothers were housewives. $14.9 \%(n=7)$ of the mothers were working.

Monthly income level: $48.9 \%(n=23)$ of the cases were low $(-1999$ TL), $46.8 \%(n=22)$ were medium (2000-4999 TL) and 4.3\% $(n=2)$ high
(5000TL and above) income level.

Number of children in the home: $23.4 \%(n=11)$ of the cases were single children, $61.7 \%(\mathrm{n}=29)$ with two children, $12.8 \%(\mathrm{n}=6)$ with three children, $2.1 \%$ $(n=1)$ were from family with four children.

Distribution of the birth order of the cases: $57.4 \%$ of the cases were first child $(n=27), 34 \%(n=$ 16) second child, $6.4 \%(n=3)$ third child, $2.1 \%(n=$ 1) was the fourth child.

Table 2. Categorical variables in terms of Denver-II language development

\begin{tabular}{|c|c|c|c|c|c|}
\hline \multicolumn{6}{|c|}{ Denver-II language outcome } \\
\hline & \multirow{2}{*}{$\begin{array}{c}\text { Total } \\
(n=58)\end{array}$} & \multirow{2}{*}{$\begin{array}{l}\text { Normal } \\
(n=27)\end{array}$} & \multirow{2}{*}{$\begin{array}{c}\text { Delayed } \\
(n=31)\end{array}$} & \multicolumn{2}{|c|}{ Statistics } \\
\hline & & & & $\chi^{2}$ & $p$ value \\
\hline \multicolumn{6}{|l|}{ Gender, n (\%) } \\
\hline Male & $43(74.1)$ & $19(70.4)$ & $24(77.4)$ & 0.374 & 0.541 \\
\hline Female & $15(25.9)$ & $8(29.6)$ & $7(22.6)$ & & \\
\hline \multicolumn{6}{|l|}{ Parents status, n (\%) } \\
\hline Together & $52(89.7)$ & $22(81.5)$ & $30(96.8)$ & $3.537^{*}$ & 0.106 \\
\hline Divorced & $5(8.6)$ & $4(14.8)$ & $1(3.2)$ & & \\
\hline Father died & $1(1.7)$ & $1(3.7)$ & 0 & & \\
\hline \multicolumn{6}{|l|}{ Mothers' work, n (\%) } \\
\hline She is working & $8(13.8)$ & $3(11.1)$ & $5(16.1)$ & $0.306^{*}$ & 0.712 \\
\hline Housewife & $50(86.2)$ & $24(88.9)$ & $26(83.9)$ & & \\
\hline \multicolumn{6}{|l|}{ Socio-economic level, n (\%) } \\
\hline Lower (-1999TL) & $25(43.1)$ & $9(33.3)$ & $16(51.6)$ & $5.450 *$ & 0.052 \\
\hline Middle (2000-4999 TL) & $30(51.7)$ & $18(66.7)$ & $12(38.7)$ & & \\
\hline High (5000 TL-) & $3(5.2)$ & 0 & $3(9.7)$ & & \\
\hline \multicolumn{6}{|l|}{ Sibling number } \\
\hline Alone, n (\%) & $12(20.7)$ & $3(11.1)$ & $9(29.0)$ & $9.045^{*}$ & 0.029 \\
\hline Two & $36(62.1)$ & $22(85.1)$ & $14(45.4)$ & & \\
\hline Three & $8(13.8)$ & $1(3.7)$ & $7(22.6)$ & & \\
\hline Four & $2(3.4)$ & $1(3.7)$ & $1(3.2)$ & & \\
\hline \multicolumn{6}{|l|}{ Birth order, n (\%) } \\
\hline First & $31(53.4)$ & $16(35.5)$ & $15(48.4)$ & $1.890^{*}$ & 0.735 \\
\hline Second & $20(34.5)$ & $9(33.3)$ & $11(35.5)$ & & \\
\hline Thirth & $5(8.6)$ & $1(3.7)$ & $4(12.9)$ & & \\
\hline Fourth & $2(3.4)$ & $1(3.7)$ & $1(3.2)$ & & \\
\hline \multicolumn{6}{|l|}{ Mothers' health, n (\%) } \\
\hline Medical disease & $3(5.2)$ & $2(7.4)$ & $1(3.2)$ & $0.514^{*}$ & 0.593 \\
\hline Psychiatric disorder & $14(24.1)$ & $6(22.2)$ & $8(25.8)$ & 0.101 & 0.750 \\
\hline
\end{tabular}

*Fisher's exact test 
Table 3. Mothers' scale scores in terms of language development of their children

\begin{tabular}{lcccccc}
\hline & \multicolumn{3}{c}{ Denver-II language outcome } & \multicolumn{2}{c}{ Statistics } \\
& $\begin{array}{c}\text { Total } \\
(\mathbf{n}=\mathbf{5 8})\end{array}$ & $\begin{array}{c}\text { Normal } \\
(\mathbf{n}=\mathbf{2 7})\end{array}$ & $\begin{array}{c}\text { Delayed } \\
(\mathbf{n}=\mathbf{3 1})\end{array}$ & & & \\
\cline { 2 - 5 } & $\mathbf{M}(\mathbf{m i n}-\mathbf{m a x})$ & $\mathbf{M}(\mathbf{m i n}-\mathbf{m a x})$ & $\mathbf{M}(\mathbf{m i n}-\mathbf{m a x})$ & $\mathbf{z}$ & $\boldsymbol{p}$ value \\
\hline BDI-total & $17(3-40)$ & $13(3-29)$ & $18(4-40)$ & -2.218 & $\mathbf{0 . 0 2 7}$ \\
BAI-total & $12(0-51)$ & $10(0-51)$ & $13(0-48)$ & & -.320 & 0.749 \\
\hline
\end{tabular}

$\mathrm{M}=$ Median, $\min =$ minimum, $\max =$ maximum

$\mathrm{BDI}=$ Beck depression inventory, BAI: Beck anxiety inventory

The medical history of the mother was $4.3 \%(\mathrm{n}=$ $2), 95.7 \%(n=45)$ of the cases. The family history of psychiatric disease was not present in $85.1 \%(\mathrm{n}=40)$ of the cases and $14.9 \%(n=7)$. Gender, demographic data of the parents, socioeconomic level, the number of children, the presence of disease histories in the mother were similar in two groups (for all $p>0.05$, see Table 2).

\section{Comparison of scale total scores}

The mean score of depression scale in the mother was significantly higher in cases with delay in language development ( 18 vs. 13 points, $\mathrm{z}=-2.218, p$ $=0.027)$. There was no significant effect of mother's anxiety symptoms on language development $(p>$ 0.05) (Table 3).

\section{Correlation analysis}

There was a negative and significant correlation between language development and Beck depression scores $(\mathrm{r}=-.294, p=0.025)$. There was a positive and significant correlation between language development and child age (month) $(\mathrm{r}=.411, p=0.001)$. There was a positive and significant correlation between mothers' educational level and language-development $(\mathrm{r}=.324$, $p=0.013$, see table 4).

\section{DISCUSSION}

In our country, there are studies investigating the developmental evaluation and the factors that affect it by using the Denver-II test. From these studies, Güneş [16] examined the effect of family functions and other demographic factors on the development of family functions using a Denver-II test in 201 mothers and their 0-6-year-old children (102 girls, 99 boys) enrolled in a family health center in a district of Bursa province [16]. They reported a positive correlation between the life satisfaction parameters of mothers and their children's developmental scores. Madan and Tekin [17] performed a total of 60 children who were selected by random sampling from children in the 0-6 age group living in the center of Antalya. Güven et al. [18] reported that 179 of the children underwent the Denver-II test to have a high socioeconomic level, factors affecting the child's development, being a child of a working mother, and being a child using breast

Table 4. Spearman correlation analysis of language development

\begin{tabular}{lccccc}
\hline & BDI-T & BAI-T & C-age (month) & M-edu (year) & F-edu (year) \\
\hline Language & $-.294^{*}$ & $\mathrm{NS}$ & $.411^{* *}$ & $.324^{* *}$ & $\mathrm{NS}$ \\
BDI-T & 1 & $.615^{* *}$ & $\mathrm{NS}$ & $\mathrm{NS}$ & $\mathrm{NS}$ \\
BAI-T & & 1 & $\mathrm{NS}$ & $\mathrm{NS}$ & $\mathrm{NS}$ \\
C-age (month) & & & 1 & $\mathrm{NS}$ & $\mathrm{NS}$ \\
M-edu (year) & & & & 1 & $.670^{* *}$ \\
\hline
\end{tabular}

$\mathrm{BDI}-\mathrm{T}=$ Beck depression inventory-Total score, BAI-T $=$ Beck anxiety inventory-Total score, $\mathrm{C}=\mathrm{Children,} \mathrm{M}$ edu $=$ Mothers' education, F-edu = Fathers' education

*significance at the 0.05 level (2-tailed), **significance at the 0.05 level (2-tailed) 
milk for longer periods[18]. Bayoglu et al. [19] conducted a total of 980 children under the Denver-II test and reported that the Denver-II test results of their children with low socioeconomic status were abnormal. Anlar et al. [20] investigated the effect of socioeconomic level on development and reported that fine-motor development was affected by this variable [20].

The common emphasis of all these studies is that this screening test is an effective tool in determining the level of development headings of children aged 0-6 with the Denver-II screening test and in following the improvements in the development steps after the required interventions.

Anlar et al. [20] found that mothers were more effective on their children's development steps than their fathers, and they indicate that this activity has reached a peak level around the age of 5 to around 3272 months. In our study, it was shown that mothers' depression symptoms had a negative effect on the language development of their children. It was not possible to test what could have changed in the stages of development after none of the cases we called for a month to check and the interventions we proposed (the behaviorist suggestions towards the mother and her child). Nevertheless, based on the current results, we can say that the mother education levels of children in the developmental period affect the language development of children. Depression symptoms in mothers of pre-school age children are important and it seems necessary to be followed up. In our study, it was determined that anxiety symptoms did not affect language-development.

\section{CONCLUSION}

This study main outcome is that there is significantly increased depressive symptoms of the mothers whose children's language development had delayed. It is important that the mothers of patients with delayed language development are referred to psychiatric evaluation for the purpose of further evaluation of depression symptoms.

\section{Conflict of interest}

The authors disclosed no conflict of interest during the preparation or publication of this manuscript.

\section{Financing}

The authors disclosed that they did not receive any grant during conduction or writing of this study.

\section{REFERENCES}

1. Tümkaya S. [Language development]. In: Deniz ME, ed., [Development in early childhood]. 8th ed., Pegem Akademi: Ankara, 2017: pp.28-52. [Article in Turkish]

2. McMurray B. Defusing the childhood vocabulary explosion. Science 2007;317:631.

3. Ekerim M, Selcuk B. Longitudinal predictors of vocabulary knowledge in Turkish children: the role of sensitive parenting and executive functions. Early Educ Dev 2018;29:324-41.

4. Garcia D, Bagner DM, Pruden SM, Nichols-Lopez K. Language production in children with and at risk for delay: mediating role of parenting skills. J Clin Child Adolesc Psychol 2015;44:814-25.

5. Stein A, Malmberg LE, Sylva K, Barnes J, Leach P; FCCC team. The influence of maternal depression, care giving, and socioeconomic status in the post-natal year on children's language development. Child Care Health Dev 2008;34:603-12. 6. Pan BA, Rowe ML, Singer JD, Snow CE. Maternal correlates of growth in toddler vocabulary production in low-income families. Child Dev 2005; 76:763-82.

7. Koutra K, Chatzi L, Bagkeris M, Vassilaki M, Bitsios P, Kogevinas M. Antenatal and postnatal maternal mental health as determinants of infant neurodevelopment at 18th months of age in a mother-child cohort (Rhea Study) in Crete, Greece. Soc Psychiatry Psychiatr Epidemiol 2013;48:1335-45.

8. Keim SA, Daniels JL, Dole N, Herring AH, Siega-Riz AM, Scheidt PC. A prospective study of maternal anxiety, perceived stress, and depressive symptoms in relation to infant cognitive development. Early Hum Dev 2011;87:373-80.

9. Frankenburg WK, Dodds J, Archer P, Shapiro H, Bresnick B. The Denver II: a major revision and restandardization of the Denver Developmental Screening Test. Pediatrics 1992;89:91-7. 10. Anlar B, Yalaz K. [Denver II Developmental Screening Test. Adaptation and standardization to Turkish children]. Hacettepe Çocuk Nörolojisi Gelişimsel Tıp Araştırmaları Grubu Yayını, Ankara. 1996. [Article in Turkish]

11. Anlar B, Bayoğlu B, Yalaz K. [Denver II test handbook adapted to Turkish children]. 2007. [Article in Turkish]

12. Beck AT, Ward CH, Mendelson M, Mock J, Erbaugh J. An inventory for measuring depression. Arch Gen Psychiatry 1961;4:561-71.

13. Hisli N. [A study on the validity of the Beck depression inventory]. Psikoloji Dergisi 1988;6:118-126. [Article in Turkish] 14. Beck AT, Epstein N, Brown G, Steer RA. An Inventory for measuring clinical anxiety: psychometric properties. J Consult Clin Psychol 1998;56:893-7.

15. Ulusoy M, Şahin N, Erkman H. Turkish version of the Beck anxiety inventory: psychometric properties. J Cogn Psychother 1998;12:163-72.

16. Günes N. [Investigation of the relationship between the 
developmental level of children aged 0-6 and their family functions and life satisfaction]. Hacettepe Üniversitesi Sağlık Bilimleri Enstitüsü. Çocuk Gelişimi ve Eğitimi Programı Yüksek Lisans Tezi (Thesis). Ankara. 2017. [Article in Turkish] 17. Madan R, Tekin D. "Developmental follow-up of 0-6 age group children" programs (PS007). Hacettepe University Faculty of Health Science Journal 2015;1(Suppl 2):641-50. [Article in Turkish]

18. Güven F, Say A, Sarı İ, Sarı E, Değirmenci S, Uygur Külcü
N. [The effect of socio-economic level on Denver II test]. Zeynep Kamil Tıp Bülteni 2012;43:108-13. [Article in Turkish]

19. Bayoğlu B, Bakar E, Kutlu M, Karabulut E, Anlar B. Can preschool developmental screening identify children at risk for school problems? Early Hum Dev 2007;83:613-7.

20. Durmazlar N, Ozturk C, Ural B, Karaagaoglu E, Anlar B. Turkish children's performance on Denver II: effects of sex and mother's education. Dev Med Child Neurol 1998;40:411-6. 